\title{
Thickness and tensile stress determination of black silicon layers by spectral reflectance and Raman scattering
}

\author{
Martin Králik*, Stanislav Jurečka*, Emil Pinčík ${ }^{* *}$
}

\begin{abstract}
In this work black silicon (b-Si) samples were prepared by anodic (electrochemical) etching of p-type silicon substrate in solution of hydrofluoric acid (HF). We studied influence of anodic etching conditions (etching time, electrical potential and current) on the spectral reflectance and Raman scattering spectra. Optical properties of b-Si structures were experimentally studied by UV-VIS (AvaSpec-2048) and Raman (Thermo DXR Raman) spectrometers. B-Si layer thickness of formed substrate were determined by using SCOUT software. Effective medium approximation theory (Looyenga) was used in construction of the reflectance model. Influence of the deformation of crystal lattice introduced during the substrate etching was studied by Raman scattering method. Teoretical model of the $1^{\text {st }}$ order Raman scattering profile was constructed by using pseudo-Voigt function and the profile parameters were extracted. The values of biaxial tensile stress were estimated by using optimized Raman profile parameters.
\end{abstract}

Keywords: Raman scattering, porous silicon, black silicon, spectral reflectance, anodic etching, electrochemical etching, SCOUT

\section{Introduction}

Porous silicon ( $\mathrm{pSi}$ ) known as black silicon (b-Si) is a highly light-absorbing material in a wide range of wavelengths. The cause of high absorption is gradual matching of the refractive index at the silicon-air interface [12]. B-Si is a sponge-like structure of monocrystalline silicon, which became one of the most well-researched silicon structures [3]. B-Si has a wide range of industrial applications (as sensors, as anodes in Lithium-ion battery, photovoltaic applications, biosensors, optoelectronics, self-cleaning coatings, etc) [3-5]. This paper deals with applications of b-Si in solar cells. Solar cells with b-Si structure achieve high efficiency (over 21\%) and stability [1]. Significant impact on efficiency of solar cell has spectral reflectance $R$. $R$ values of $\mathrm{Si}$ are over $40 \%$ in range of spectrum relevant for solar cell applications. This high spectral reflectance can be reduced by using antireflection layers or by additional surface treatment of Si. The anti-reflective coatings ensure a reduction in reflectivity to approximately $6 \%$. Reflectivity of high-quality b-Si samples is below $1.5 \%$ [6]. The use of b-Si in conventional production of solar cells is complicated by twoo factors: increased surface recombination due to the larger surface area of the nanostructures and Auger recombination at the highly-doped nanostructures $[1,7]$. Experiments on pin-hole free and highly conformal atomic layer deposited (ALD) thin films combined with the chemical and field effect passivation ability of $\mathrm{Al}_{2} \mathrm{O}_{3}$ published by
H. Savin et al can solve problem of surface recombination of b-Si [1].

Porous silicon (pSi) may be divided into three categories based on classification of porous materials as a function of their pore size $d_{\mathrm{p}}$ (IUPAC - International Union of Pure and Applied Chemistry): microporous silicon $(\mu \mathrm{pSi})$ with $d_{\mathrm{p}}<2 \mathrm{~nm}$, mesoporous silicon $(\mathrm{mpSi})$ with $2 \mathrm{~nm}<d_{\mathrm{p}}<50 \mathrm{~nm}$, macroporous silicon $(\mathrm{MpSi})$ with $d_{\mathrm{p}}>50 \mathrm{~nm}$. Based on morphological details, pSi may be divided into two categories: sponge-like $\mathrm{pSi}(\mu \mathrm{pSi}$ and $\mathrm{mpSi}$ ), pSi featuring cylindrical pores with rough or smooth walls (MpSi) $[3,8]$. The size and shape of the pores of b-Si can be affected by the technical parameters of production. Reduction of pore size can be achieved with anodization when using an lightly-doped p-type $\mathrm{Si}$ substrate, by using low current density in the process of etching or use of highly concentrated hydrofluoric acid HF (more than 40\%) [9].

Mesoporous silicon can be prepared by electrochemical etching of highly doped p-type or n-type Si substrate $\left(\mathrm{p}^{+}\right.$-type $\mathrm{Si}, \mathrm{p}^{++}$-type $\mathrm{Si}, \mathrm{n}^{+}$-type $\mathrm{Si}, \mathrm{n}^{++}$-type $\left.\mathrm{Si}\right)$. Resistivity of $\mathrm{p}^{++}$-type $\mathrm{Si}$ is about $1 \mathrm{~m} \Omega \mathrm{cm}$. The result of electrochemical etching of $\mathrm{p}^{++}$-type substrate is a smaller number of pores with a larger diameter. The pore diameter can be controlled by the current density. Macroporous silicon can be prepared by electrochemical etching of n-type Si substrate, while the backside is illuminated. In this way, uniform-diameter macropores can be formed [9, 10-11]. Key parameters of MpSi production by using electrochemical etching method are: electrolyte

*Institute of Aurel Stodola, Faculty of Electrical Engineering, University of Žilina, ul. kpt. J. Nálepku 1390, 03101 Liptovský Mikuláš, Slovakia, martin.kralik@fel.uniza.sk, **Institute of Physics, Slovak Academy of Sciences, Dúbravská cesta 9, 84511 Bratislava, Slovakia 
type, HF concentration, the surfacant, the Si doping type, the Si doping level, backside illumination, frontside illumination, etc [9].

There are several methods to produce b-Si: anodic etching, stain etching, photoetching, metal-assisted chemical etching, vapor etching, reactive-ion etching, spark erosion, laser-induced plasma erosion, etc [3]. Monocrystalline silicon (mono-Si) wafers produced by the Czochralski method is the most commonly used substrate to produce b-Si $[1,12]$. The most suitable method of producing $\mathrm{b}-\mathrm{Si}$ is reactive plasma etching. Reactive plasma etching has three dominant advantages over other methods (like is wet etching, metal-assisted chemical etching, laserinduced etching, etc): toxic chemicals are not used, structure size and shape can be easy controled and mask-less processing [12].

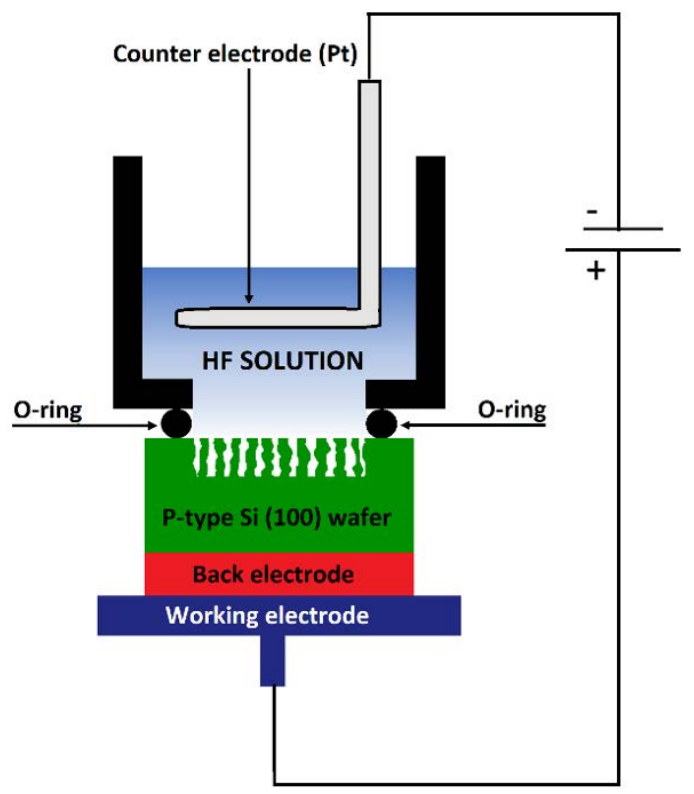

Fig. 1. Basic schematic of electrochemical etching method

The electrochemical etching of Si wafers in HF solution is most common method of b-Si production [3]. The basic schematic of electrochemical etching method (single cell configuration) is shown i n Fig. 1. The basic components of the system for the electrochemical etching are anode, cathode, electrolyte, cell, o-rings [10-11]. The following materials may be used to produce a cell body: PVC (polyvinylchlorid), PP (polypropylene), PTFE (polytetrafluoroethylene) and PVDF (polyvinylidene fluoride). These materials are resistant to HF $[8,11]$. Ensuring of accessibility of the back of the sample is possible by the use of o-rings. The back of the sample can thus be used to create a ohmic contact, what will ensure homogeneous current density distribution [11]. The cathode is usually platinum due to its high chemical resistivity. The ohmic contact on the backside of sample (by ion implantation or by depositing a thin metal layer such as $\mathrm{Al}$ for p-type $\mathrm{Si}$ and $\mathrm{Au}-\mathrm{Sb}$ for n-type $\mathrm{Si}$ ) must be ensured for the lightly doped silicon $\left(<10^{18} \mathrm{~cm}^{3}\right)$. During etching, the back or front of the n-type Si sample must be illuminated by high intensity white light [9]. There are two modes of etching of silicon depending on current density: pore formation $\left(J>J_{\mathrm{PSL}}\right)$ and electropolishing $\left(J<J_{\mathrm{PSL}}\right)[3,11,13]$. Regimes of silicon electrochemical etching in HF: porous silicon formation and the electropolishing are shown in Fig. 2.

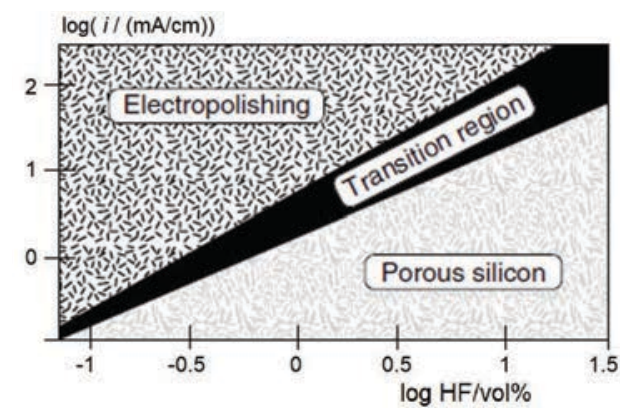

Fig. 2. Regimes of silicon electrochemical etching in HF [14]

The reactions that take place in HF electrolyte are given by equation (pore formation, low current density) [13]

$$
\mathrm{Si}+6 \mathrm{HF} \longrightarrow \mathrm{H}_{2} \mathrm{SiF}_{6}+\mathrm{H}_{2}+2 \mathrm{H}^{+}+2 \mathrm{e}^{-} .
$$

The reactions for electropolishing at high current density are given by equation

$$
\mathrm{Si}+6 \mathrm{HF} \longrightarrow \mathrm{H}_{2} \mathrm{SiF}_{6}+4 \mathrm{H}^{+}+4 \mathrm{e}^{-} .
$$

There are three electrochemical cell configurations for pSi formation: lateral cell, single cell and double cell. In first (lateral) and second (single cell) electrochemical cell configurations the silicon sample serves as the anode. The main problem of lateral cell is the inhomogeneous distribution of current density, which causes nonuniform porosity and thickness of formed pSi structure. Single cell configuration is the most frequently used configuration due to its advantages: the possibility of creating a ohmic contact on the back of the sample, homogeneous current density distribution, possibility to illuminate the back side of the sample (needed for n-type $\mathrm{Si}$ ), porosity and thickness uniformity. Double cell configuration allows optimization of the pSi layer uniformity. The cell is divided into two parts and separated by etched silicon sample. As anode and cathode platinum electrodes are used. Part of the double cell configuration is also a chemical pump that ensures circulation of electrolyte. By using chemical pump, the hydrogen bubbles are removed from electrolyte and their attachment to the Si surface is prevented [3].

Samples published in this work were prepared by anodic etching method described by 1,2 . During intensive etching procedure b-Si layers are formed. Properties of these b-Si layers are influenced by the conditions of technological treatment operations. For applications in solar cells the thickness of formed layers is important as it directly influences spectral reflectance values. We determined the thickness of studied b-Si layers by construction 
of theoretical model of the spectral reflectance, depending on layer thickness, structural inhomogeneities and estimation of material dielectric functions by using the effective media approximation. During anodic etching crystal structure of silicon substrate is severely damaged. Deformations of crystal lattice introduce stress and influence structural stability. We studied biaxial tensile stress values by the Raman scattering method.

\section{Experimental details}

The b-Si structures were prepared by anodic etching of p-type Si substrate in HF solution. Properties of resulting structures are determined mainly by applied voltage, current density and etching time. We experimentally studied properties of b-Si layers formed under various etching conditions. The thickness of produced layer is significantly determined by etching time. Parameters of anodic etching procedure used in this work are shown in Tab. 1.

Table 1. Electrochemical etching conditions

\begin{tabular}{lcccc}
\hline Sample & $\begin{array}{c}\text { Etching } \\
\text { time } \\
(\mathrm{s})\end{array}$ & $\begin{array}{c}\text { Current } \\
\text { density } \\
\left(\mathrm{mA} / \mathrm{cm}^{2}\right)\end{array}$ & $\begin{array}{l}\text { Voltage } \\
(\mathrm{V})\end{array}$ & Substrate \\
\hline $7 / 2 / 3$ & 150 & 50 & 3.3 & p-type \\
$7 / 3 / 3$ & 300 & 50 & 6.4 & p-type \\
\hline
\end{tabular}

After etching samples were annealed in oxygen atmosphere for 10 minutes at $850^{\circ} \mathrm{C}$. Spectral reflectance of samples was analyzed by using UV-VIS spectrophotometer AvaSpec-2048. The combination of deuterium and halogen lamps was used as a light source in the wavelength range $200-1100 \mathrm{~nm}$. Aluminium mirror was used as a reference sample. The Raman scattering spectra were measured by using THERMO SCIENTIFIC DXR Raman spectrometer. Before sample measurement the device calibration and background measurement were performed. The laser radiation with wavelength of $532 \mathrm{~nm}$ and power of $5 \mathrm{~mW}$ was used for the scattering excitation.

\section{Results and discussion}

\subsection{Determination of thickness of b-Si layer from the spectral reflectance}

Determination of the thin film thickness from the spectral reflectance can be performed by several methods. One of the methods is based on the theory of thin film interference. This method is based on using following equation [14-15]

$$
d=\frac{m}{2 \sqrt{n^{2}-\sin ^{2} \theta}}\left(\frac{1}{\lambda_{1}}-\frac{1}{\lambda_{2}}\right)^{-1}
$$

where $d(\mathrm{~nm})$ is thin film thickness, $m$ is the number of peaks in the wavelength range used for calculation, $n$ is refractive index of thin-film, $\lambda_{1}$ and $\lambda_{2} \mathrm{~nm}$ are the start and end wavelengths in the wavelength range used for calculation. This method can be used only for homogeneous thin films, because this relationship neglect the refractive index dispersion. Determination of the thickness of b-Si layer by using 3 can help in initial d estimation. In the porous silicon a gradual change of the refractive index is observed. Another important factor influencing the calculation of layer thickness is roughness at the interfaces air/b-Si and b-Si/Si [16]. For these reasons, the thickness calculation of b-Si layers and optical constants (refractive index, extinction coefficient) determination requires a different approach.

The most accurate method is based on theoretical modeling of the spectral reflectance. Theoretical modeling can be divided into three steps: 1 . dividing the measured sample into the layer system (number of layers, roughness at the interfaces, etc), 2. selecting a suitable optical function for each layer, 3. optimization of constructed model [17]. Optical parameters of pSi layers have very complex dependence on the layer microstructure and creating a suitable optical model is essential [18]. Several functions for creating a theoretical dispersion model can be used: New Amorphous Dispersion Formula (NADF, for amorphous materials exhibiting an absorption in the visible and far UV range - absorbing dielectrics, semiconductors, polymers) [19], Lorentz Dispersion Model (transparent or weakly absorbing materials - insulators, semiconductors) [20], Tauc-Lorentz dispersion formula (amorphous materials exhibiting an absorption in the visible and far UV range - absorbing dieletrics, semiconductors, polymers) [21], Briot dispersion formula (transparent materials) [22] and other. In construction of the spectral reflectance model an effective medium approximations (EMA) are usually used. Frequently used EMA theories involve Maxwell-Garnett, Bruggeman, Lorentz-Lorentz, Drude and Looyenga theories [16, 23-27]. Spectral reflectances of b-Si layers were modelled in the SCOUT software by using Looyenga EMA approach suitable for porous structures, [16]. The Looyenga EMA formula is

$$
\tilde{\varepsilon}_{\mathrm{eff}}^{1 / 3}=(1-p) \tilde{\varepsilon}_{\mathrm{m}}^{1 / 3}+p \tilde{\varepsilon}_{\mathrm{p}}^{1 / 3}
$$

where $p$ is porosity, $\varepsilon_{\mathrm{m}}$ is complex dielectric function of matrix material and $\varepsilon_{\mathrm{p}}$ is complex dielectric function of particle material. Values of complex dielectric functions of matrix and particle materials were taken from literature (Edward D. Palik, Handbook of Optical Constants of Solids). Relationship between complex refractive index and complex dielectric constant, [27], is

$$
\tilde{n}(\lambda)=\sqrt{\tilde{\varepsilon}(\lambda)}
$$

$$
\operatorname{Re}(\tilde{n})=\frac{1}{\sqrt{2}}\left[\varepsilon_{\text {real }}+{\sqrt{\varepsilon_{\text {real }}^{2}+\varepsilon_{\text {imag }}^{2}}}^{1 / 2}=\sqrt{\frac{|\widetilde{\varepsilon}|+\varepsilon_{\text {real }}}{2}}\right.
$$


Table 2. Modelling of the spectral reflectance

\begin{tabular}{lccc}
\hline Sample & EMA model & EMA fractions & Layer thickness $(\mathrm{nm})$ \\
\hline $7 / 2 / 3$ & Looyenga & $\mathrm{c}-\mathrm{Si}\left(\varepsilon_{\mathrm{m}}\right), \mathrm{SiO}_{2}\left(\varepsilon_{\mathrm{p}}\right)$ & 477.4 \\
$7 / 3 / 3$ & Looyenga & $\mathrm{c}-\mathrm{Si}\left(\varepsilon_{\mathrm{m}}\right), \mathrm{SiO}_{2}\left(\varepsilon_{\mathrm{p}}\right)$ & 1290.5 \\
\hline
\end{tabular}
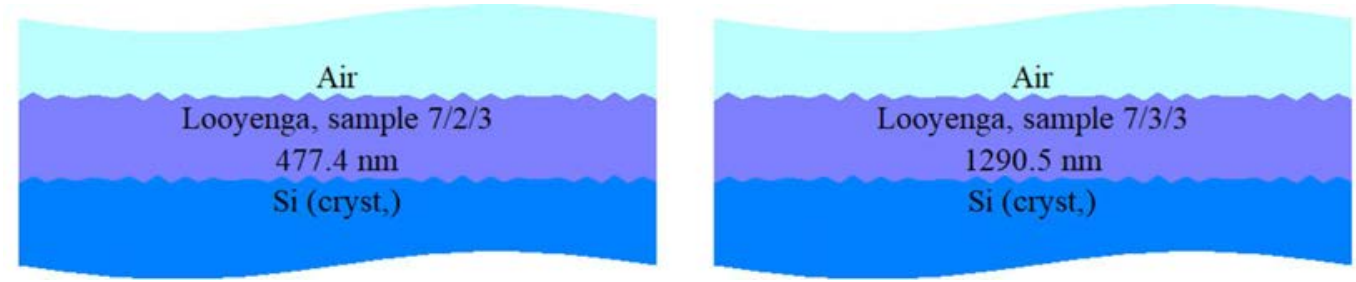

Fig. 3. Theoretical model of sample $7 / 2 / 3$ (left) and $7 / 3 / 3$ (right) used in SCOUT software

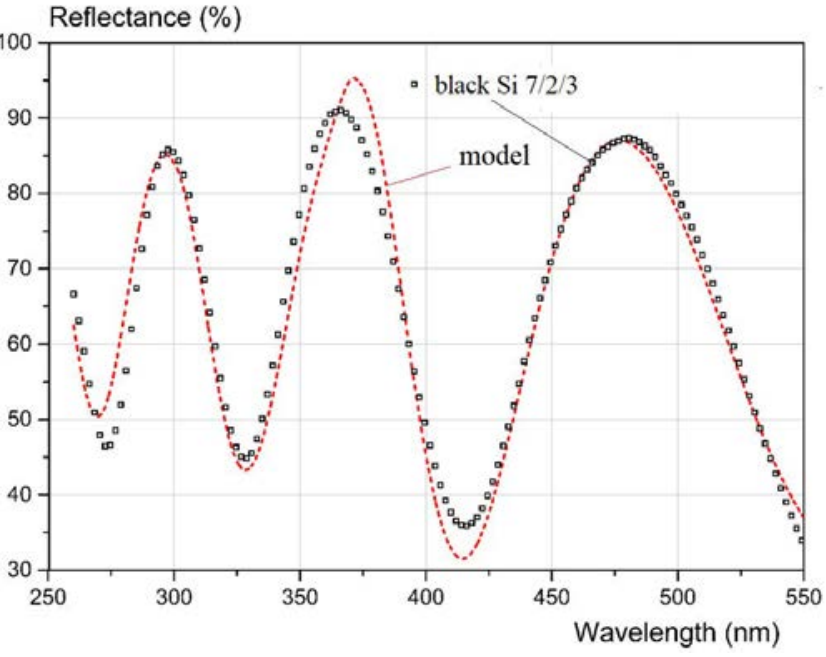

Fig. 4. Experimental spectral reflectance (squares) and optimized theoretical model (red) for sample $7 / 2 / 3$

$$
\operatorname{Im}(\tilde{n})=\frac{1}{\sqrt{2}}\left[\sqrt{\varepsilon_{\text {real }}^{2}+\varepsilon_{\text {imag }}^{2}}-\varepsilon_{\text {real }}\right]^{1 / 2}=\sqrt{\frac{|\widetilde{\mid}|-\varepsilon_{\text {real }}}{2}}
$$

Theoretical models are based on geometrical configuration proposed by Fig. 3. The volume fractions used in the Looyenga EMA function are chosen for description of porous media formed by anodic etching and passivated by thermal oxidation step. These volume fractions are $\mathrm{SiO}_{2}$ and crystalline silicon (c-Si). The dielectric functions of volume fractions used in the Looyenga EMA are shown in Table 2. With increasing of etching time, the thickness of b-Si layers increases. It is caused by prolongation of etching time accompanied by continued forming of porous microstructure on the surface of silicon. The resulting thicknesses of b-Si layers are shown in Table 2. Experimental spectral reflectances and optimized theoretical models are shown in Fig. 4 and Fig. 5. More significant deviations of theoretical models from experimental spectral

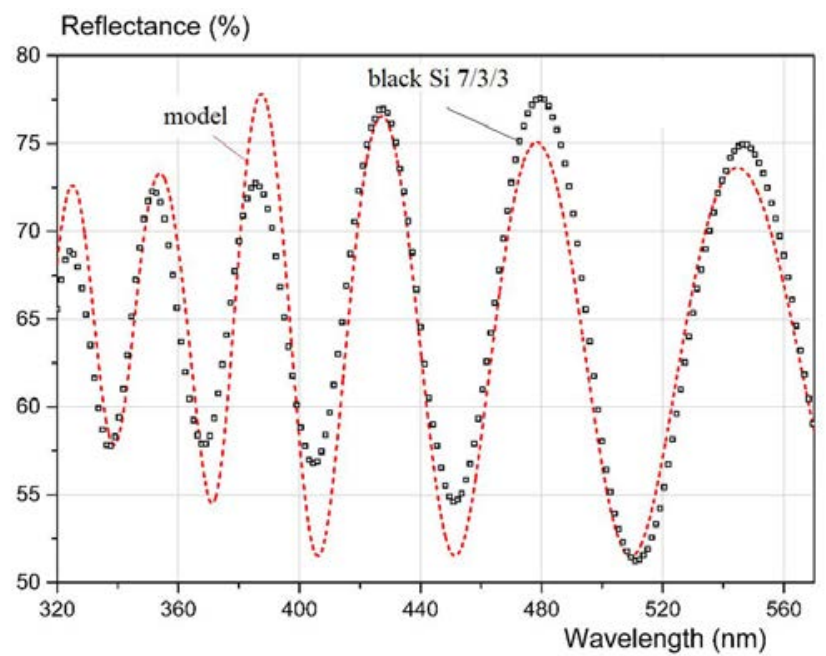

Fig. 5. Experimental spectral reflectance (squares) and optimized theoretical model (red) for sample $7 / 3 / 3$

reflectances are observed in wavelength region around 400 $\mathrm{nm}$ (sample $7 / 3 / 3$ ). It is caused by complexity of formed porous structure described by relative simple effective media approximation constructed by using expected $\mathrm{Si}$ and $\mathrm{SiO}_{2}$ components. Further improvement of theoretical model requires development of more complex effective media approximation with accounting of additional volume fractions introduced in the passivation step and description of the interplay between complicated porosity structure and space composition of individual EMA components.

\subsection{Raman scattering}

Samples $7 / 2 / 3$ and $7 / 3 / 3$ prepared by anodic etching method were experimentally studied by the Raman spectroscopy method. We paid special attention to spectral region centered around $520 \mathrm{~cm}^{-1}$, where the $1^{\text {st }}$ order of Si Raman profile is positioned. The shape of the $1^{\text {st }}$ 
Table 3. Raman scattering

\begin{tabular}{lcccc}
\hline Sample & $\begin{array}{c}\text { Raman profile center } \\
\left(\mathrm{cm}^{-1}\right)\end{array}$ & $\begin{array}{c}\Delta \nu \\
\left(\mathrm{cm}^{-1}\right)\end{array}$ & $\begin{array}{c}\text { Biaxial tensile stress } \\
(\mathrm{MPa})\end{array}$ & $\begin{array}{c}\text { Raman intensity } \\
\text { (a.u. })\end{array}$ \\
\hline Si substrate & 520.4 & - & - & 1865 \\
$7 / 2 / 3$ & 520.2 & -0.2 & 50 & 3950 \\
$7 / 3 / 3$ & 520.175 & -0.225 & 56.25 & 2795 \\
\hline
\end{tabular}

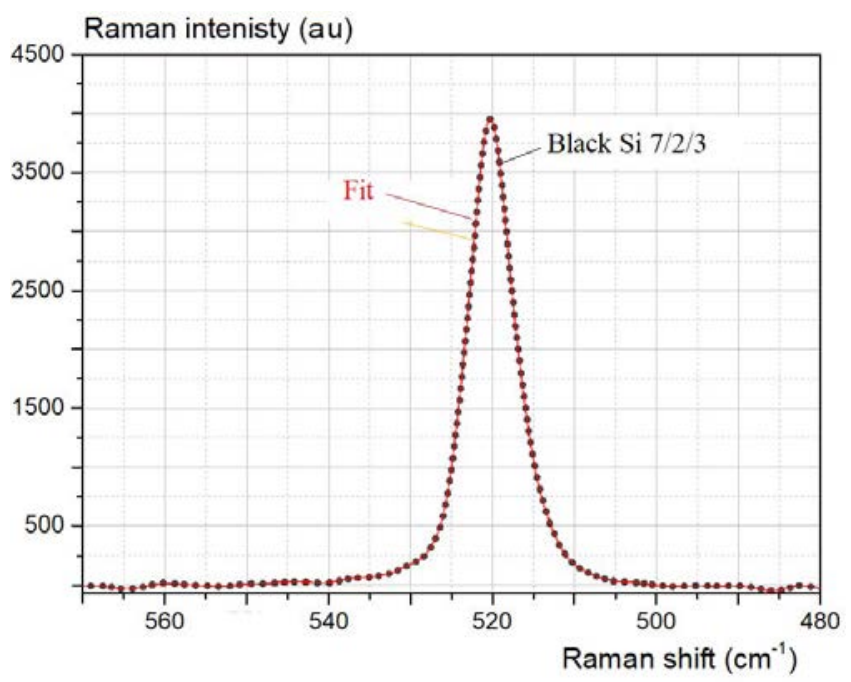

Fig. 6. Raman scattering (dots) of sample $7 / 2 / 3$ and mathematical model (red)

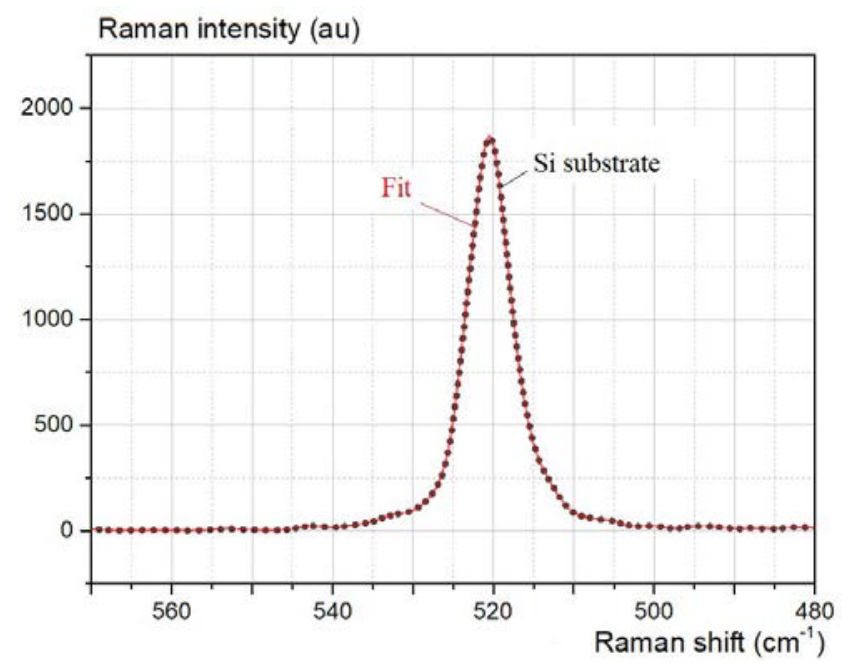

Fig. 8. Raman scattering (dots) of p-type Si substrate and mathematical model (red)

order Raman scattering profile of black Si structure provide information about deformation of crystal lattice in the etching procedure. The conservation of phonon momentum $q$ in crystalline silicon structure enables Raman active optical phonon mode at the central zone $(q=0)$ with wavenumber around $522 \mathrm{~cm}^{-1}$, which gives rise to

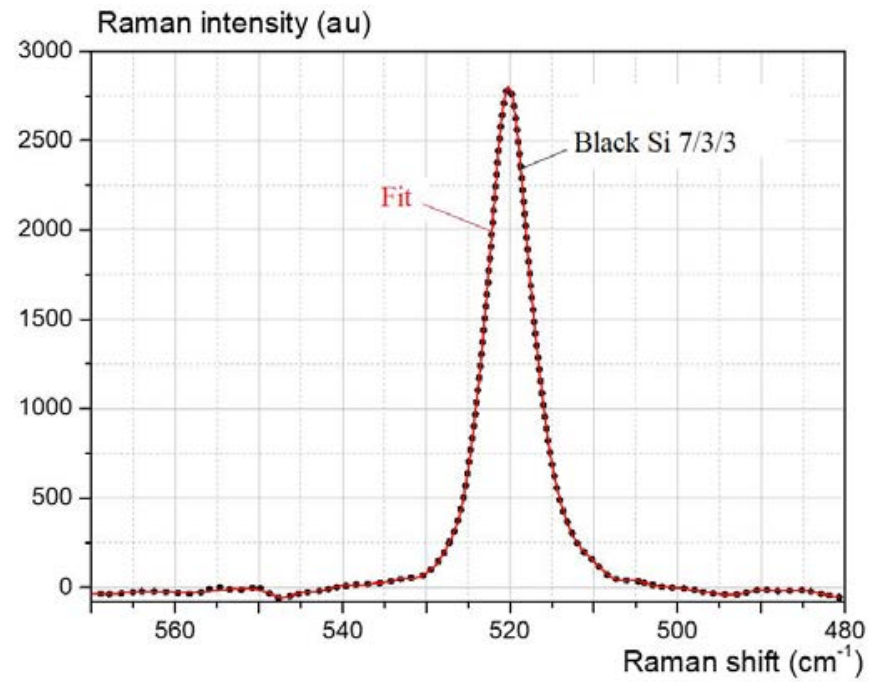

Fig. 7. Raman scattering (dots) of sample $7 / 3 / 3$ and mathematical model (red)

a single profile with a width FWHM $\sim 3.5 \mathrm{~cm}^{-1}$ at room temperature [28]. The shape of this scattering profile characterized by the central profile position, width and Raman intensity is influenced by the etching treatment. In order to estimate the values of profile parameters we modelled experimental Raman scattering data by the pseudo-Voigt function. The pseudo-Voigt function is defined by equation

$$
\begin{array}{r}
y=y_{0}+A\left[m_{\mathrm{u}} \frac{2}{\pi} \frac{w}{4\left(x-x_{\mathrm{c}}\right)^{2}+w^{2}}\right]+ \\
A\left[\left(1-m_{\mathrm{u}}\right) \frac{\sqrt{4 \ln 2}}{\sqrt{\pi} w} \exp \left(-\frac{4 \ln 2}{w^{2}}\left(x-x_{\mathrm{c}}\right)^{2}\right)\right]
\end{array}
$$

where $y_{0}$ offset, $x_{\mathrm{c}}$ centre, $A$ amplitude, $w$ FWHM and $m_{\mathrm{u}}$ are the parameters of modelling function. This profile function contains information about Gaussian and Lorentzian component frequently used for desription of experimentally observed profiles in Raman spectroscopy. Values of these parameters extracted from optimized Raman profile model are listed in Table 3 . The $1^{\text {st }}$ order experimental Raman scattering profile (dots), mathematical model of analysed samples (red) and Raman profile of Si substrate are shown in Fig. 6, Fig. 7, and Fig. 8. From optimized Raman profile functions the central peak 


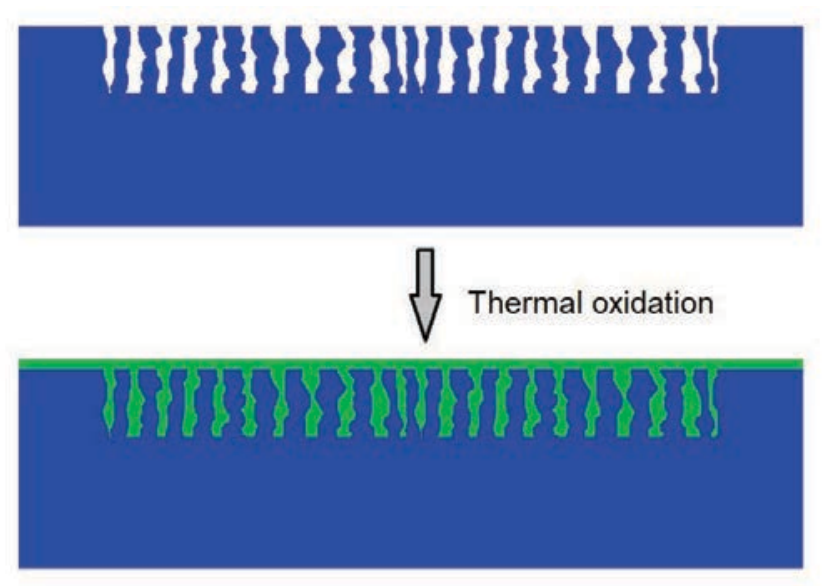

Fig. 9. Effect of the thermal annealing of b-Si, (green: $\mathrm{SiO}_{2}$, blue: $\mathrm{c}-\mathrm{Si})$

position was extracted and used for determination of biaxial tensile stress introduced by etching procedure. The biaxial tensile stress values $T S$ were evaluated by using equation

$$
T S=-250(M P A) \Delta \nu \quad\left(\mathrm{cm}^{-1}\right)
$$

where $\Delta \nu$ is shift of central profile position of etched layer $\Delta \nu=\nu_{\mathrm{c}}(\mathrm{bSi})-\nu_{\mathrm{c}}(\mathrm{Si})$. The values of Raman profile center, shift of the profile center and calculated biaxial tensile stress are listed in Table 3.

With prolongation of etching time the value of biaxial tensile stress increases. It is caused by increasing deformations of the crystal structure introduced by the etching procedure.

\section{Conclusions}

This work deals with experimental study of black silicon by using spectral reflectance and Raman scattering. The samples were prepared by electrochemical etching method. The thickness of b-Si layers was determined from the spectral reflectance measurements. Theoretical model of spectral reflectance was constructed by using Looyenga effective media approximation ferequently used in description of porous media. The microstructure of etched porous Si layers passivated by thermal annealing is relatively complex and requires development of adequate effective media approximation model. We used standard EMA approach based on relatively small number of structural components. After anodic etching the samples were thermally oxidized. Thermal oxidation forms an $\mathrm{SiO}_{2}$ layer on the sample surface. We suppose that the pores were closed in the upper sublayers, which prevents the diffusion of oxygen to the remaining structure [4]. This process is illustrated in Fig. 9. For this reason, two volume fractions $\left(\mathrm{SiO}_{2}\right.$ and $\left.\mathrm{c}-\mathrm{Si}\right)$ were used in the EMA modelling. From resulting spectral reflectance model we estimated the b-Si layer thicknesses. We expected and observed increasing thickness of etched layers with increasing etching time due to the etching mechanism described by 1 and 2 . Refinement of theoretical spectral reflectance model requires detailed knowledge about the space distribution of material fractions contained in complicated porous microstructure of formed b-Si layers.

The b-Si samples were studied by analysis of the $1^{\text {st }}$ order Raman scattering profile. The biaxial tensile stress values connected with the shift of the center of the Raman scattering profile were determined. The central profile position was extracted from optimized pseudo-Voigt profile function used for the description of Raman scattering. With prolongation of etching time the values of the biaxial tensile stress increase. It is caused by continuing etching of silicon substrate accompanied by introduced tensile stress.

\section{Acknowledgements}

The work was supported by project H2020-MSCARISE-2016-6260922, grant of Science and Technology Assistance Agency APVV-15-0152, Scientific Grant Agency of the Ministry of Education of Slovak Republic and the Slovak Academy of Sciences project VEGA 1/0676/17, Centre of Excellence of Power Electronics Systems and Materials ITMS 26220120003, No. OPVaV-2008/2.1/01SORO, ITMS 26220120046, and by project ITMS 26210120021, co-funded from EU sources and European Regional Development Fund.

\section{REFERENCES}

[1] H. Savin, P. Repo, G. von Gastrow, P. Ortega, E. Calle, M. Garín and R. Alcubilla, "Black silicon solar cells with interdigitated back-contacts achieve $22.1 \%$ efficiency", Nature Nanotechnology, vol. 10, pp. 624-628, 2015.

[2] P. B. Clapham and M. C. Hutley, "Reduction of Lens Reflexion by the "Moth Eye" Principle", Nature, vol. 244, pp. 281-282, 1973.

[3] F. Karbassian, Porous Silicon, IntechOpen Limited, London, 2018.

[4] B. Fodor, E. Agocs, B. Bardet, T. Defforge, F. Cayrel, D. Alquier, M. Fried, G. Gautier and P. Petrik, "Porosity and thickness characterization of porous $\mathrm{Si}$ and oxidized porous Si layersan ultraviolet-visible-mid infrared ellipsometry study", Microporous and Mesoporous Materials, vol. 227, pp. 112-120, 2016.

[5] N. J. Hutchinson, T. Coquil, A. Navid and L. Pilon, "Effective optical properties of highly ordered mesoporous thin films", Thin Solid Films, vol. 518, pp. 2141-2146, 2010.

[6] D. Raghunathan, "Black silicon for higher efficiency in solar cells", Applied Mechanics and Materials, vol. 787, pp. 92-96, 2015.

[7] J. Oh, H.-Ch. Yuan and H. M. Branz, "An 18.2\%-efficient black-silicon solar cell achieved through control of carrier recombination in nanostructures", Nature Nanotechnology, vol. 7, pp. 743-748, 2012.

[8] D. Losic, Electrochemically Engineered Nanoporous Materials Methods, Properties and Applications, Springer, 2015.

[9] L. Canham, Handbook of Porous Silicon, Springer, 2014. 
[10] M. J. Sailor, Porous Silicon in Practice, Wiley-VCH Verlag \& Co. KGaA, Weinheim, 2012.

[11] V. Lehmann, Electrochemistry of Silicon, Wiley-VCH Verlag \& Co. KGaA, Weinheim, 2002.

[12] M. Pakhotnyuk, R. S. Davidsen, M. S. Schmidt, R. Malureanu, E. Stamate, O. Hansen, "Lifetime of Nano-Structured Black Silicon for Photovoltaic Applications", Proceedings of 32nd European Photovoltaic Solar Energy Conference and Exhibition, pp. 764-767, 2016.

[13] S. Franssila, Introduction to Microfabrication, Second Edition, John Wiley \& Sons, Ltd., Chichester, 2010.

[14] A. R. Hind and L. Chomette, The determination of thin film thickness using reflectance spectroscopy - Application Note, Agilent Technologies, Inc., 2011.

[15] T. Hine, UV Talk Letter, Schimazu, vol. 1, 2008.

[16] C. F. Ramirez-Gutierrez, J. D. Castano-Yepes and M. E. Rodriguez-Garcia, "Porosity and roughness determination of porous silicon thin films by genetic algorithms", Optik, vol. 173, pp. 271-278, 2018.

[17] H. G. Tompkins and E. A. Irene, Handbook of Ellipsometry, William Andrew, Inc., Norwich, 2005.

[18] Z. Montiel-González, S. Escobar, R. Nava, J. A. del Río and J. Tagüena-Martínez, "Role of an Oxidant Mixture as Surface Modifier of Porous Silicon Microstructures Evaluated by Spectroscopic Ellipsometry", Scientific Reports, 2016.

[19] Horiba, New Amorphous Dispersion Formula - Technical Note, vol. TN12, 2006.
[20] Horiba, Lorentz Dispersion Formula - Techn. Note, vol. TN02, 2006.

[21] Horiba, Tauc-Lorentz Dispersion Formula - Technical Note, vol. TN11, 2006.

22] Horiba, Cauchy and related Empirical Dispersion Formulae for Transparent Materials - Technical Note, vol. NT14, Horiba, 2006.

23] H. Sohn, Refractive Index of Porous Silicon, Springer International Publishing Switzerland, 2014

[24] A. Navid and L. Pilon, "Effect of polarization and morphology on the optical properties of absorbing nanoporous thin films", Thin Solid Films, vol. 516, pp. 4159-4167, 2008.

[25] A. Garahan, L. Pilon and J. Yin, "Effective optical properties of absorbing nanoporous and nanocomposite thin films", Journal of Applied Physics, vol. 101, pp. 014320, 2007.

[26] M. M. Braun and L. Pilon, "Effective optical properties of non-absorbing nanoporous thin films", Thin Solid Films, vol. 496, pp. 505-514, 2006.

[27] N. J. Hutchinson, T. Coquil, E. K. Richman, S. H. Tolbert and L. Pilon, "Reflectance of surfactant-templated mesoporous silica thin films: Simulations versus experiments", Thin Solid Films, vol. 518, pp. 2134-2140, 2010.

[28] H. Richter, Z. P. Wang and L. Ley, "The one phonon Raman spectrum in microcrystalline silicon", Solid State Communications, vol. 39, pp. 625-629, 1981.

Received 19 March 2019 